\title{
Effects of atrial fibrillation on complications and prognosis of patients receiving emergency PCI after acute myocardial infarction
}

\author{
YINGCHUN ZHANG ${ }^{1}$, LINGZHI ZHANG ${ }^{2}$, HONGZHI ZHENG ${ }^{3}$ and HONGFEN CHEN ${ }^{1}$ \\ Departments of ${ }^{1}$ Emergency, ${ }^{2}$ Stomatology and ${ }^{3}$ Public Health, Affiliated Hospital of Weifang Medical University, \\ Weifang, Shandong 261031, P.R. China
}

Received January 29, 2018; Accepted August 2, 2018

DOI: $10.3892 / \mathrm{etm} .2018 .6640$

\begin{abstract}
The effects of atrial fibrillation on complications and prognosis of patients receiving emergency percutaneous coronary intervention after acute myocardial infarction (AMI) were investigated. Eighty AMI patients treated with interventional vascular recanalization in the Affiliated Hospital of Weifang Medical University (Weifang, China) from July 2015 to October 2016 were selected, including 40 patients complicated with atrial fibrillation before operation (control group) and 40 patients without atrial fibrillation before operation (observation group). The systolic blood pressure, diastolic blood pressure, heart rate, arrhythmia and common complications after MI were compared. Changes in the coronary artery thrombolysis in myocardial infarction (TIMI) flow grade and left ventricular ejection fraction (LVEF) of patients were also recorded. Moreover, changes in brain natriuretic peptide (BNP) levels were compared. The recovery time of myocardial enzyme and total troponin in both groups was recorded. The systolic and diastolic blood pressure in the observation group were significantly higher than those in the control group $(\mathrm{p}<0.05)$. During the intervention, the total proportion of patients with ventricular arrhythmia, atrial arrhythmia, atrioventricular block and sinus tachycardia in the observation group was significantly lower than that in the control group $(\mathrm{p}<0.05)$. The total proportion of common complications after $\mathrm{MI}$ in the observation group was obviously lower than that in the control group $(\mathrm{p}<0.05)$. Coronary artery TIMI flow grades and LVEFs in the observation group were obviously higher than those in the control group. BNP levels in the observation group were significantly lower than those in the control group. The recovery time of myocardial enzyme
\end{abstract}

Correspondence to: Dr Hongfen Chen, Department of Emergency, Affiliated Hospital of Weifang Medical University, 2428 Yuhe Road, Weifang, Shandong 261031, P.R. China

E-mail: c2m849@163.com

Key words: atrial fibrillation, acute myocardial infarction, percutaneous coronary intervention, complications and total troponin in the observation group was significantly earlier than that in the control group. Atrial fibrillation has a certain negative effect on the circulatory function in patients with AMI after the interventional therapy, and the proportions of arrhythmia and complications in patients after MI are increased at the same time, so the postoperative recovery of patients is slow with many complications.

\section{Introduction}

Atrial fibrillation is one of the most common arrhythmias in clinic. When patients are complicated with acute myocardial infarction (AMI), the risk of atrial fibrillation is even higher than $15 \%$ (1). Atrial fibrillation complications may lead to an increase in ventricular rate, further increasing the myocardial oxygen consumption, and aggravating myocardial ischemia and hypoxia (2). A large number of studies have confirmed (3-5) that atrial fibrillation is an independent risk factor for MI in patients with coronary heart disease. After coronary heart disease develops into AMI, the mortality rate of patients may be significantly increased if they are complicated with atrial fibrillation. At present, revascularization can be performed effectively via percutaneous coronary intervention (PCI) for AMI patients complicated with atrial fibrillation, ensuring the reperfusion of ischemic myocardium (6). However, there are few literature studies on the effect of atrial fibrillation (new-onset or complicated previously) on the prognosis of patients receiving PCI after MI. In order to fill in the above gap, effects of atrial fibrillation on complications and prognosis of patients receiving emergency PCI after AMI were mainly investigated in this study.

\section{Materials and methods}

General data. A total of 80 AMI patients treated with interventional vascular recanalization in the Affiliated Hospital of Weifang Medical University (Weifang, China) from July 2015 to October 2016 were selected and received electrocardiogram examination when enrolled, including 40 patients complicated with atrial fibrillation before operation (control group) and 40 patients without atrial fibrillation before operation (observation group). The patients signed the 
informed consent when enrolled, and this study was approved by the Ethics Committee of the Affiliated Hospital of Weifang Medical University (Weifang, China). They were aged 40-60 years with a survival time of more than 1 year. Patients complicated with heart failure, definite primary myocardial disease before operation, severe pulmonary infection, mental illness, coagulation disorders, platelet dysfunction, systemic immune system disease, other arrhythmia before onset, and pregnant and/or breastfeeding patients were eliminated. In observation group, there were 40 patients without atrial fibrillation, including 21 males and 19 females. In terms of atrial fibrillation type, there were 35 cases of acute atrial fibrillation, and 5 cases of chronic atrial fibrillation. The implementation time of interventional treatment was $1-12 \mathrm{~h}$ with an average of $5.1 \pm 0.3 \mathrm{~h}$. In the control group, there were 40 patients complicated with atrial fibrillation, including 20 males and 20 females. In terms of atrial fibrillation type, there were 34 cases of acute atrial fibrillation, and 6 cases of chronic atrial fibrillation. The implementation time of the interventional treatment was $1-12 \mathrm{~h}$ with an average of $5.0 \pm 0.3 \mathrm{~h}$. There were no statistically significant differences in comparisons of sex, age, atrial fibrillation type and implementation time of the interventional treatment between the two groups $(\mathrm{p}>0.05)$.

Treatment methods. After admission, all patients received continuous electrocardiogram monitoring for $24 \mathrm{~h}$, and dynamic electrocardiogram monitoring for $24 \mathrm{~h}$. The onset time, duration, and predisposing factors of patients complicated with atrial fibrillation were recorded, and vital signs of patients at the onset were clear. Operation standards of PCI were as follows: After treatment, the stenosis rate of the remaining parts in the coronary lumen should be $<20 \%$, and coronary artery thrombolysis in myocardial infarction (TIMI) flow grade reaches grade 3. In perioperative PCI, $300 \mathrm{mg}$ clopidogrel [NMPN J20130083, manufactured by Sanofi Winthrop Industrie (Floirac, France), subpackaged by Sanofi Pharmaceutical Co., Ltd. (Hangzhou, China)] was taken at a draught each time, followed by oral administration of $75 \mathrm{mg}$ clopidogrel per day for 12 consecutive months after operation. At the same time, $300 \mathrm{mg}$ aspirin was taken at a draught before operation, followed by oral administration of $100 \mathrm{mg}$ aspirin/day after operation for a long term.

Observation indexes. The patients were followed up for 1 year. The systolic and diastolic blood pressure, heart rate, arrhythmia and common complications after MI were compared between the two groups at 1 month after intervention. Changes in coronary artery TIMI flow grade and left ventricular ejection fraction (LVEF) of patients before operation, immediately after operation, and at 3 months and 1 year after operation were also compared. Moreover, changes in the brain natriuretic peptide (BNP) levels before operation and at 1 week and 1 month after operation were compared. Finally, the recovery time of myocardial enzyme and total troponin in both groups were recorded.

Evaluation criteria. Coronary artery TIMI flow grade is divided into a total of 4 grades (grade $0-3$ ) as follows: Grade 0 , there is no blood flow or perfusion; grade 1, there is very little blood flow or perfusion, and contrast agent can be seen only
Table I. Comparison of systolic blood pressure, diastolic blood pressure and heart rate at 1 month after intervention between the two groups (mean $\pm \mathrm{SD}$ ).

\begin{tabular}{lccc}
\hline Groups & $\begin{array}{c}\text { Systolic blood } \\
\text { pressure (mmHg) }\end{array}$ & $\begin{array}{c}\text { Diastolic blood } \\
\text { pressure }(\mathrm{mmHg})\end{array}$ & $\begin{array}{c}\text { Heart rate } \\
\text { (time/min) }\end{array}$ \\
\hline Observation & $105.6 \pm 2.7$ & $68.9 \pm 1.1$ & $87.5 \pm 2.9$ \\
Control & $85.3 \pm 1.9$ & $47.6 \pm 0.6$ & $98.6 \pm 3.6$ \\
t-test & 38.888 & 107.513 & 15.186 \\
P-value & 0.001 & 0.001 & 0.001 \\
\hline
\end{tabular}

Table II. Comparison of arrhythmia between the two groups (n).

\begin{tabular}{lcccc}
\hline Groups & $\begin{array}{c}\text { Ventricular } \\
\text { arrhythmia }\end{array}$ & $\begin{array}{c}\text { Atrial } \\
\text { arrhythmia }\end{array}$ & $\begin{array}{c}\text { Atrioventricular } \\
\text { block }\end{array}$ & $\begin{array}{c}\text { Sinus } \\
\text { tachycardia }\end{array}$ \\
\hline Observation & 1 & 2 & 1 & 2 \\
Control & 10 & 13 & 9 & 11 \\
$\chi^{2}$ & 6.746 & 8.205 & 5.600 & 5.878 \\
P-value & 0.009 & 0.004 & 0.018 & 0.015 \\
\hline
\end{tabular}

in the occluded site; grade 2, there is partial blood flow or perfusion, and contrast agent can pass the occluded site and reach the distant end, but the filling rate is lower than normal; and grade 3 , there is normal blood flow or perfusion. BNP was detected via micro-particle enzyme immunoassay, and its normal range is $0-38 \mathrm{pg} / \mathrm{ml}$. Serum lactic dehydrogenase (LDH) was detected via velocity method, and its normal range is 100-240 U/1. Creatine kinase-MB (CK-MB) was detected via colorimetric method, and its normal range is $0-25 \mathrm{IU} / 1$. The level of cardiac troponin (cTn), including cTnT, cTnI and cTnC, $>1.0 \mu \mathrm{g} / \mathrm{l}$ was used as a critical value of diagnosis of AMI.

Statistical analysis. Statistical Product and Service Solutions (SPSS) 13.0 software (SPSS, Inc., Chicago, IL, USA) was used. Measurement data are presented as mean \pm standard deviation (mean $\pm \mathrm{SD}$ ). $\mathrm{t}$-test was used for the comparison of means between the two groups, and Chi-square test was used for the intergroup comparison of rates. $\mathrm{P}<0.05$ was considered to indicate a statistically significant difference.

\section{Results}

Comparison of systolic and diastolic blood pressure as well as heart rate at 1 month after intervention between the two groups. At 1 month after intervention, the systolic and diastolic blood pressure in the observation group were significantly higher than those in the control group $(\mathrm{p}<0.05)$, but the heart rate was lower than that in the control group $(\mathrm{p}<0.05)$ (Table I).

Comparison of arrhythmia between the two groups. During the intervention, the total proportion of patients with ventricular arrhythmia, atrial arrhythmia, atrioventricular block and sinus tachycardia in the observation group was significantly lower than that in the control group $(\mathrm{p}<0.05)$ (Table II). 
Table III. Comparison of common complications after MI between the two groups (n).

Total

Ventricular Cardiac Mural Syndromes incidence

Groups aneurysm rupture thrombosis after MI rate

\begin{tabular}{llllllc}
\hline Observation & 2 & 0 & 2 & 1 & $5(12.5 \%)$ \\
Control & 6 & 1 & & 7 & 3 & $17(42.5 \%)$ \\
$\chi^{2}$ & & & - & & & 9.028 \\
P-value & & & - & & & 0.001
\end{tabular}

Table IV. Comparison of recovery time of myocardial enzyme and total troponin between the two groups (mean $\pm \mathrm{SD}$ ).

\begin{tabular}{lccc}
\hline Groups & LDH (days) & CK-MB (h) & Total troponin (days) \\
\hline Observation & $8.1 \pm 0.2$ & $65.3 \pm 2.1$ & $11.3 \pm 0.5$ \\
Control & $9.6 \pm 0.3$ & $71.2 \pm 3.1$ & $13.7 \pm 0.9$ \\
t-test & 26.312 & 9.966 & 14.743 \\
P-value & 0.001 & 0.001 & 0.001 \\
\hline
\end{tabular}

Comparison of common complications after MI between the two groups. During the 1-year follow-up after operation, the total proportion of common complications after MI, such as ventricular aneurysm, cardiac rupture, mural thrombosis and syndromes after MI, in the observation group was obviously lower than that in the control group $(\mathrm{p}<0.05)$ (Table III).

Changes in coronary artery TIMI blood flow grades of patients at different time-points before and after operation. There was no statistically significant difference in the coronary artery TIMI flow grade between the two groups before operation (grade $0.3 \pm 0.3$ vs. $0.3 \pm 0.1, \mathrm{t}=0.000, \mathrm{p}>0.05$ ) (Fig. 1 ). The coronary artery TIMI flow grades in the observation group immediately after operation, and at 3 months and 1 year after operation were grade $(2.6 \pm 0.3),(2.3 \pm 0.3)$ and $(2.1 \pm 0.2)$, respectively, which were significantly higher than those in the control group (grade 2.2 $\pm 0.2,2.0 \pm 0.2$ and 1.7 \pm 0.1$)(t=7.016$, 5.262 and $11.314, \mathrm{p}<0.05)$.

Changes in LVEFs of patients at different time-points before and after operation. There was no statistically significant difference in LVEF between the two groups before operation $(32.5 \pm 1.5$ vs. $32.6 \pm 1.5 \%, t=0.298, p=0.766>0.05)$ (Fig. 2 ). LVEFs in the observation group immediately after operation, and at 3 months and 1 year after operation were $(41.5 \pm 2.0$, $56.1 \pm 2.6$ and $61.1 \pm 2.7 \%$ ), respectively, which were significantly higher than those in the control group $(38.6 \pm 1.8,49.7 \pm 2.0$ and $53.5 \pm 2.6 \%)(\mathrm{t}=6.816,12.340$ and $12.823, \mathrm{p}<0.05)$.

Changes in BNP levels of patients at different time-points before and after operation. There was no statistically significant difference in the BNP level between the two groups before operation $(1285.6 \pm 23.6$ vs. $1286.5 \pm 23.5 \mathrm{mg} / \mathrm{l}, \mathrm{t}=0.171$, $\mathrm{p}=0.865>0.05)$ (Fig. 3). The BNP levels in the observation group at 1 week and 1 month after operation were (356.6 \pm 15.1

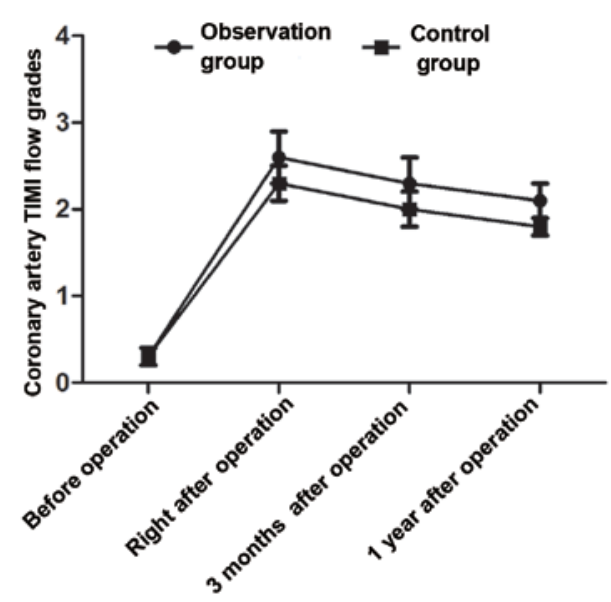

Figure 1. Changes in coronary artery TIMI blood flow grades of patients at different time-points before and after operation. Coronary artery TIMI flow grades in the observation group immediately after operation, and at 3 months and 1 year after operation are obviously higher than those in the control group during the same period $(\mathrm{p}<0.05)$. TIMI, thrombolysis in myocardial infarction.

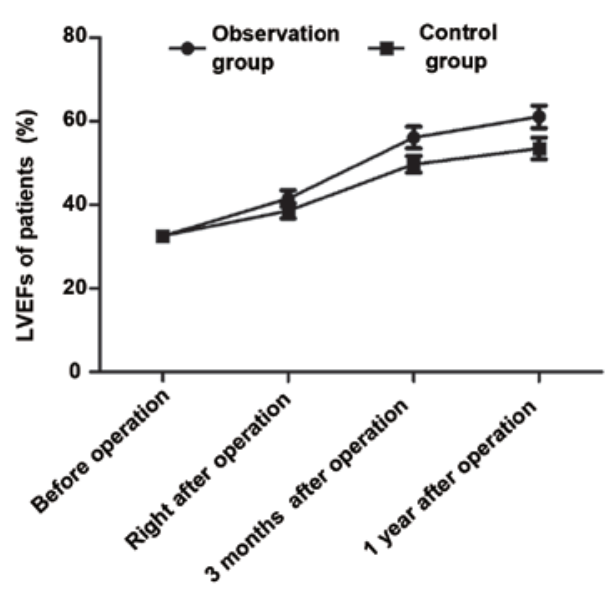

Figure 2. Changes in LVEFs of patients at different time-points before and after operation. LVEFs in the observation group immediately after operation, and at 3 months and 1 year after operation are obviously higher than those in the control group during the same period $(\mathrm{p}<0.05)$. LVEF, left ventricular ejection fraction.

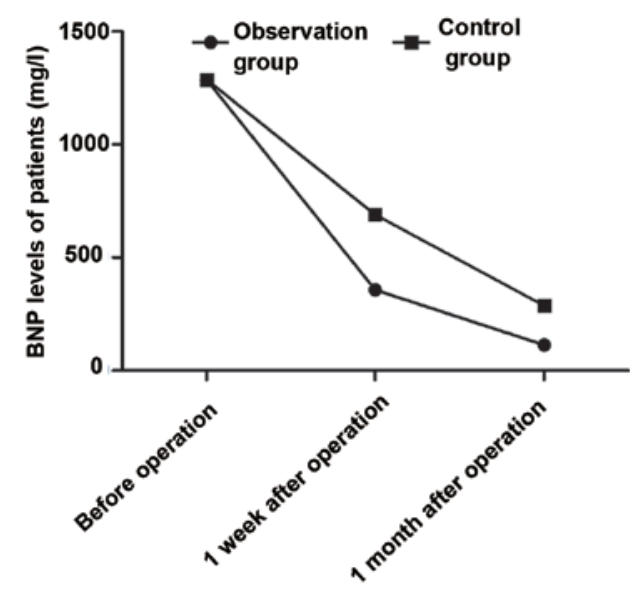

Figure 3. Changes in the BNP levels of patients at different time-points before and after operation. At 1 week and 1 month after operation, the BNP levels in the observation group are significantly lower than those in the control group during the same period $(\mathrm{p}<0.05)$. BNP, brain natriuretic peptide. 
and $113.2 \pm 5.1 \mathrm{mg} / \mathrm{l})$, respectively, which were obviously lower than those in the control group $(689.9 \pm 20.8$ and $286.9 \pm 9.5 \mathrm{mg} / \mathrm{l})$ $(\mathrm{t}=82.012$ and $101.886, \mathrm{p}<0.05)$.

Comparison of recovery time of myocardial enzyme and total troponin between the two groups. The recovery time of myocardial enzyme and total troponin in the observation group was significantly earlier than that in thw control group $(\mathrm{p}<0.05)$ (Table IV).

\section{Discussion}

Currently, the pathogenesis of AMI complicated with atrial fibrillation is not yet fully understood in clinic, among which sinoatrial node ischemia (7) and decreased electrical stability of myocardium (8) are common theories. In AMI patients complicated with atrial fibrillation, the lesion is often located in the right coronary artery, and the possible reason is that the obstruction of the right coronary artery is prone to cause sinoatrial hypofunction, affecting sinus rhythm (9). At the same time, the electrical stability of myocardium is decreased, leading to atrial fibrillation. If AMI patients are complicated with atrial fibrillation, the cardiac output may be further reduced, increasing ventricular rate, causing further imbalance between myocardial oxygen supply and demand, aggravating myocardial ischemia and hypoxia, and even expanding the infarct size, ultimately inducing and aggravating heart failure and even resulting in cardiac arrest in patients (10). Timely PCI is currently the most effective treatment method for AMI (11). At present, there is abundant literature worldwide mainly on research on prognosis of AMI patients complicated with atrial fibrillation, but literature on the effect of atrial fibrillation on PCI after AMI is scarce.

In this study, AMI patients undergoing PCI were divided into the observation group (without atrial fibrillation) and the control group (complicated with atrial fibrillation) according to whether they were complicated with atrial fibrillation. All patients were followed up for 1 year. Comparisons of systolic and diastolic blood pressure as well as heart rate between the two groups at 1 month after intervention showed that systolic and diastolic blood pressure in the observation group were significantly higher than those in the control group, but the heart rate was lower than that in the control group, suggesting that the postoperative circulatory function of patients without atrial fibrillation is more stable with better recovery. In addition, the research on arrhythmia and common complications after MI in both groups showed that the proportion of patients with ventricular arrhythmia, atrial arrhythmia, atrioventricular block and sinus tachycardia in the observation group was significantly lower than that in control group, and the total proportion of common complications after MI, such as ventricular aneurysm, cardiac rupture, mural thrombosis and syndromes after MI, in the observation group was obviously lower than that in the control group, indicating that arrhythmia, ventricular aneurysm, cardiac rupture, mural thrombosis and syndromes after MI seldom occur in patients without atrial fibrillation receiving PCI after MI. At the same time, it was found during the follow-up that the coronary artery TIMI flow grades and LVEFs in the observation group immediately after operation, and at 3 months and 1 year after operation were obviously higher than those in the control group during the same period, and at 1 week and 1 month after operation, the BNP levels in the observation group were significantly lower than those in the control group during the same period, suggesting that in patients without atrial fibrillation, the effect of vascular recanalization is better. The maintenance time is longer, and postoperative LVEF can be recovered rapidly and effectively, thus reducing myocardial damage and improving prognosis of patients. Finally, the recovery time of myocardial enzyme and total troponin was compared between the two groups, and it was found that the recovery time of myocardial enzyme and total troponin in the observation group was significantly earlier than that in the control group, further proving that the postoperative recovery of patients without atrial fibrillation is quicker.

Performing vascular recanalization in coronary artery in the early stage, and maintaining myocardial perfusion, thus quickly and effectively relieving myocardial ischemia and hypoxia (12) have important values in increasing and improving the sinoatrial node arterial blood supply and reducing postoperative complications in AMI patients. Once MI occurs in patients complicated with atrial fibrillation before operation, especially rapid atrial fibrillation (13), cardiac function is prone to decline significantly (14), thereby aggravating myocardial ischemia via positive feedback, and increasing infarct size (15). Although timely interventional vascular recanalization is effective, it is difficult to improve sinoatrial node function in a short time, especially for patients with chronic atrial fibrillation (16). The long-term atrial fibrillation may result in mural thrombus shedding after MI, thus causing thromboembolic disease (17). Meanwhile, atrial fibrillation complicated before operation may further reduce the cardiac function of patients, increase ventricular rate and myocardial oxygen consumption (18), and lead to hemodynamic disorders, thereby increasing myocardial infarct size (19), even inducing heart failure and aggravating myocardial damage (20).

In conclusion, atrial fibrillation has a certain negative effect on circulatory function in patients with AMI after interventional therapy, and the proportions of arrhythmia and complications in patients after MI are increased at the same time, so the postoperative recovery of patients is slow and with many complications.

\section{Acknowledgements}

Not applicable.

\section{Funding}

No funding was received.

\section{Availability of data and materials}

The datasets used and/or analyzed during the present study are available from the corresponding author on reasonable request.

\section{Authors' contributions}

YZ contributed to the conception and design of the study and provided statistical methods. LZ performed the research and collected and analyzed the data of this study. HZ was responsible for carrying out additional analysis and interpreting 
the results. $\mathrm{HC}$ wrote the initial draft, revised and finalized this study and was responsible for the treatment of patients. All authors have read and approved the final manuscript.

\section{Ethics approval and consent to participate}

This study was approved by the Ethics Committee of Affiliated Hospital of Weifang Medical University (Weifang, China). Signed informed consents were obtained from the patients or guardians.

\section{Patient consent for publication}

Not applicable.

\section{Competing interests}

The authors declare that they have no competing interests.

\section{References}

1. Batra G, Friberg L, Erlinge D, James S, Jernberg T, Svennblad B, Wallentin L and Oldgren J: Antithrombotic therapy after myocardial infarction in patients with atrial fibrillation undergoing percutaneous coronary intervention. Eur Heart J Cardiovasc Pharmacother 6: 36-45, 2018.

2. Chen J, Wang LY, Deng C, Jiang XH and Chen TG: The safety and efficacy of oral anticoagulants with dual versus single antiplatelet therapy in patients after percutaneous coronary intervention: A meta-analysis. Medicine (Baltimore) 96: e8015, 2017. doi: 10.1097/MD.0000000000008015.

3. Cannon CP, Bhatt DL, Oldgren J, Lip GYH, Ellis SG, Kimura T, Maeng M, Merkely B, Zeymer U, Gropper S, et al; RE-DUAL PCI Steering Committee and Investigators: Dual antithrombotic therapy with dabigatran after PCI in atrial fibrillation. N Engl J Med 377: 1513-1524, 2017.

4. Hwang KK, Eom SY, Lee SY, Kim SM, Cho MC, Kim YJ, Seung KB, Jeong MH and Bae JW; other Korea Acute Myocardial Infarction Registry Investigators: Atrial fibrillation on admission is related with higher mortality in ST-segment elevation myocardial infarction patients. Int Heart J 58: 486-494, 2017.

5. Zhai HB, Liu J, Dong ZC, Wang DX and Zhang B: Current use of oral anticoagulants and prognostic analysis in patients with atrial fibrillation undergoing coronary stenting. Chin Med J (Engl) 130: 1418-1423, 2017.

6. Ispas AF, Mangin L, Paziuc A and Belle L: Unexpected evolution of a non-stenotic lesion in the left main coronary artery of a patient with non-ST-segment elevation myocardial infarction. Cardiovasc Diagn Ther 7: 340-344, 2017.

7. Choi HI, Ahn JM, Kang SH, Lee PH, Kang SJ, Lee SW, Kim YH, Lee CW, Park SW, Park DW, et al: Prevalence, management, and long-term (6-year) outcomes of atrial fibrillation among patients receiving drug-eluting coronary stents. JACC Cardiovase Interv 10: 1075-1085, 2017.

8. Topaz G, Flint N, Steinvil A, Finkelstein A, Banai S, Keren G, Shacham Y and Yankelson L: Long term prognosis of atrial fibrillation in ST-elevation myocardial infarction patients undergoing percutaneous coronary intervention. Int J Cardiol 240: 228-233, 2017.

9. Gwyn JCV, Thomas MR and Kirchhof P: Triple antithrombotic therapy in patients with atrial fibrillation undergoing percutaneous coronary intervention: A viewpoint. Eur Heart J Cardiovasc Pharmacother 3: 157-162, 2017.
10. Romanov A, Martinek M, Pürerfellner H, Chen S, De Melis M, Grazhdankin I, Ponomarev D, Losik D, Strelnikov A, Shabanov V, et al: Incidence of atrial fibrillation detected by continuous rhythm monitoring after acute myocardial infarction in patients with preserved left ventricular ejection fraction: Results of the ARREST study. Europace 20: 263-270, 2018.

11. Bogacki P, Kabłak-Ziembicka A, Bryniarski K, Wrotniak L, Ostrowska-Kaim E, Żmudka K and Przewłocki T: Triple anticoagulation therapy in patients with atrial fibrillation undergoing percutaneous coronary intervention - real life assessment. Postepy Kardiol Interwencyjnej 12: 303-313, 2016.

12. Chaudhary N, Bundhun PK and Yan H: Comparing the clinical outcomes in patients with atrial fibrillation receiving dual antiplatelet therapy and patients receiving an addition of an anticoagulant after coronary stent implantation: A systematic review and meta-analysis of observational studies. Medicine (Baltimore) 95: e5581, 2016.

13. Gibson CM, Mehran R, Bode C, Halperin J, Verheugt FW, Wildgoose $\mathrm{P}$, Birmingham $\mathrm{M}$, Ianus $\mathrm{J}$, Burton $\mathrm{P}$, van Eickels M, et al: Prevention of bleeding in patients with atrial fibrillation undergoing PCI. N Engl J Med 375: 2423-2434, 2016.

14. Zehir R, Tekkesin AI, Haykir N, Velibey Y, Borklu EB and Gumusdag A: Peak troponin I level predicts new-onset atrial fibrillation in patients with myocardial infarction. Clin Invest Med 39: E213-E219, 2016.

15. Prami T, Khanfir H, Deleskog A, Hasvold P, Kytö V, Reissell E and Airaksinen J: Clinical factors associated with initiation of and persistence with ADP receptor-inhibiting oral antiplatelet treatment after acute coronary syndrome: A nationwide cohort study from Finland. BMJ Open 6: e012604, 2016.

16. Bagai A, Wang TY, Goodman SG, Fisher HN, Welsh RC, Dery JP, Zhang X, Zhu YE, Cheema AN, Dehghani P, et al; Canadian Observational AntiPlatelet sTudy (COAPT) Investigators: Longitudinal treatment patterns with ADP receptor inhibitors after myocardial infarction: Insights from the Canadian Observational AntiPlatelet sTudy. Int J Cardiol 228: 459-464, 2017.

17. Cannon CP, Gropper S, Bhatt DL, Ellis SG, Kimura T, Lip GY, Steg PG, Ten Berg JM, Manassie J, Kreuzer J, et al; RE-DUAL PCI Steering Committee and Investigators: Design and Rationale of the RE-DUAL PCI Trial: A prospective, randomized, phase $3 \mathrm{~b}$ study comparing the safety and efficacy of dual antithrombotic therapy with dabigatran etexilate versus warfarin triple therapy in patients with nonvalvular atrial fibrillation who have undergone percutaneous coronary intervention with stenting. Clin Cardiol 39: 555-564, 2016.

18. Dekkers OM, Horváth-Puhó E, Cannegieter SC, Vandenbroucke JP, Sørensen HT and Jørgensen JO: Acute cardiovascular events and all-cause mortality in patients with hyperthyroidism: A population-based cohort study. Eur J Endocrinol 176: 1-9, 2017.

19. Hudzik B, Szkodziński J, Hawranek M, Lekston A, Poloński L and Gassior M: CHA2DS2-VASc score is useful in predicting poor 12-month outcomes following myocardial infarction in diabetic patients without atrial fibrillation. Acta Diabetol 53: 807-815, 2016.

20. Masuda M,NakataniD, Hikoso S, Suna S, Usami M, Matsumoto S, Kitamura T, Minamiguchi H, Okuyama Y, Uematsu M, et al; OACIS Investigators: Clinical impact of ventricular tachycardia and/or fibrillation during the acute phase of acute myocardial infarction on in-hospital and 5-year mortality rates in the percutaneous coronary intervention era. Circ J 80: 1539-1547, 2016.

This work is licensed under a Creative Commons Attribution-NonCommercial-NoDerivatives 4.0 International (CC BY-NC-ND 4.0) License. 